\title{
A randomized, open-label clinical trial using optical coherence tomography to compare two sirolimus-eluting stents, one with a biodegradable polymer and the other with a permanent polymer
}

\author{
FENG TIAN, YUNDAI CHEN, CHANGFU LIU, QINHUA JIN, LIAN CHEN, \\ ZHIJUN SUN, HONGBIN LIU, JUN GUO and LUYUE GAI
}

Department of Cardiology, Chinese PLA General Hospital, Beijing 100853, P.R. China

Received October 15, 2012; Accepted January 15, 2013

DOI: $10.3892 / \mathrm{mmr} .2013 .1313$

\begin{abstract}
Intimal hyperplasia appears to differ after implanting a drug-eluting stent (DES) with a biodegradable or a permanent polymer. The aim of the present study was to compare biodegradable with permanent polymer DES, since the available data are limited. One hundred patients with de novo coronary artery stenosis were included in this study. The patients were classified into 2 groups: DES with a biodegradable polymer $(n=50)$ and DES with a permanent polymer $(n=50)$. Optical coherence tomography (OCT) examination was performed before and after stent implantation. A follow-up OCT, performed 1 year after stent implantation, compared the morphologies of intimal hyperplasia in the 2 groups. The frequencies of uncovered stent struts (2.27 vs. $1.87 \%, \mathrm{P}=0.145)$ and stent strut malapposition (1.9 vs. $2.02 \%$, $\mathrm{P}=0.655$ ) upon the first-year follow-up were not significantly different. Average neointimal thickness was lower in the biodegradable compared with the permanent polymer group $(106.12 \pm 80.65$ vs. $181.20 \pm 146.96 \mu \mathrm{m}, \mathrm{P}<0.001)$. The frequencies of neointimal thickness $<100 \mu \mathrm{m}$ were significantly higher in the biodegradable compared with the permanent polymer group (62.1 vs. $35.9 \%, \mathrm{P}<0.001)$. The average intimal thickness was also lower in the biodegradable compared with the permanent polymer group $(57.7 \pm 24.6$ vs. $67.6 \pm 22.4 \mu \mathrm{m}$, $\mathrm{P}<0.001$ ). In conclusion, biodegradable polymer DES resulted in significantly lower intimal hyperplasia and had wellproportioned intimal coverage compared with permanent polymer DES.
\end{abstract}

Correspondence to: Dr Yundai Chen, Department of Cardiology, Chinese PLA General Hospital, No. 28 Fuxing Road, Haidian District, Beijing 100853, P.R. China

E-mail: yundaichen@yahoo.cn

Key words: optical coherence tomography, drug-eluting stent, biodegradable polymer, coronary heart disease

\section{Introduction}

Interventional cardiology with drug-eluting stents (DES) has significantly improved the treatment of coronary atherosclerotic disease, and it has currently become the gold standard. However, with the advent of using DES to treat complex lesions, the risk of stent thrombosis has also increased $(1,2)$, and late stent thrombosis has been reported following DES implantation (3). Long-term treatment with dual anti-platelet therapy following stent implantation has provided a solution to counteract the risk of stent thrombosis. However, this treatment has risks and is expensive. An additional problem of DES is delayed endothelialization, which may be a contributing factor to the prolonged period of thrombotic risk, as shown by pathological findings from autopsies following DES implantation. These investigations have shown that even after 16 months, intimal healing is still incomplete with $\sim 20 \%$ of stent struts uncovered (4). These problems of late thrombosis and delayed endothelialization of stent struts with DES may be caused by the permanent polymer used to bond the anti-restenosis compounds to the stents. To confirm this speculation, intravascular ultrasonography and angiography have been previously used to gain information on DES (5). These techniques provide 2- and 3-dimensional views of the vessel.

However, with intravascular ultrasonography, shadowing occurs around and behind the stent struts since they are reflectors of sonic waves. Intravascular ultrasonography is also characterized by limitations in detecting the malapposition of the struts to the vessel wall, especially when the area between the vessel wall and the strut is small. Optical coherence tomography (OCT) is a novel imaging modality that visualizes intracoronary features with an axial resolution of 3-20 $\mu \mathrm{m}$, which is substantially higher resolution compared with that of intravascular ultrasonography $(100-150 \mu \mathrm{m})$. OCT is able to detect intimal coverage upon the follow-up of DES more clearly and accurately $(6,7)$. The present study aimed to assess and compare the presence and morphology of intimal hyperplasia following the implantation of DES with a biodegradable polymer vs. the DES with a permanent polymer using OCT. 


\section{Materials and methods}

Study design. This was a prospective, randomized, open-label, single-center study designed to assess and compare intimal hyperplasia using OCT following implantation of either a stent with a biodegradable polymer (Excel; JW Medical Systems, Weihai, China) or a stent with a permanent polymer (Cypher ${ }^{\circledR}$; Cordis, Fremont, CA, USA). One hundred patients with de novo coronary artery stenosis were included in this study. Half of the participants received each type of stent. A member of the research team approached each patient to obtain written informed consent before percutaneous coronary intervention or any study-related procedure, and each patient signed the consent form prior to enrollment. All the procedures were approved by the Local Ethics Committee.

Inclusion and exclusion criteria. The inclusion criteria included age, $30-75$ years; binary stenosis, $\geq 70 \%$ in a de novo lesion in the native coronary artery; reference lumen diameter proximal to the target lesion, 2.5 and $\leq 4.0 \mathrm{~mm}$; lesion length $\leq 30 \mathrm{~mm}$; and signed, written informed consent.

The exclusion criteria included pregnancy or breastfeeding, intolerance to aspirin or clopidogrel, acute myocardial infarction, congestive heart failure (left ventricular ejection fraction $<40 \%$ ), renal insufficiency (serum creatinine $>1.8 \mathrm{mg} / \mathrm{dl}$ ), left main coronary artery disease, chronic total occlusion, ostium lesion, severely tortuous arteries, history of revascularisation and no signed informed consent.

Stent implantation. The patients were administered aspirin (100 mg/day), clopidogrel (300 mg loading dosage, $75 \mathrm{mg} /$ day) and heparin at a dose of $100 \mathrm{U} / \mathrm{kg}$ before the procedure. Percutaneous coronary intervention procedure was performed according to the standard technique. Stent implantation was conducted following the manufacturer's instructions of each stent.

Clinical and coronary angiography follow-up. The patients underwent follow-up evaluations 1 year after stent implantation. Major adverse cardiac events were noted and stored in our database. Such events included cardiac death, heart failure, myocardial infarction ( $\mathrm{Q}$ and non-Q waves), as well as ischemia-driven target lesion revascularization. The patients underwent coronary angiography at 1 year of follow-up after stent implantation.

OCT image acquisition and analysis. The patients underwent 3 OCT examinations, which were performed before and after stent implantation, and at the first-year follow-up. The M3 OCT system (LightLab Imaging, Inc., Westford, MA, USA) was used in the current study. The speed of the automatic pullback was $1.5 \mathrm{~mm} / \mathrm{sec}$. The image included the entire length of the stent and $\mathrm{a} \geq 5-\mathrm{mm}$ segment beyond the stent edges. The OCT images were analyzed offline by 2 independent blinded doctors. The software used was provided by LightLab Imaging, Inc. A single OCT cross-sectional still frame was selected for quantitative analysis from each 1-mm segment throughout the entire length of the stent. The still frames were selected based on the appearance of stent struts, and the lack of OCT motion artifacts or other image artifacts. The coronary plaque was classified as fibrous,

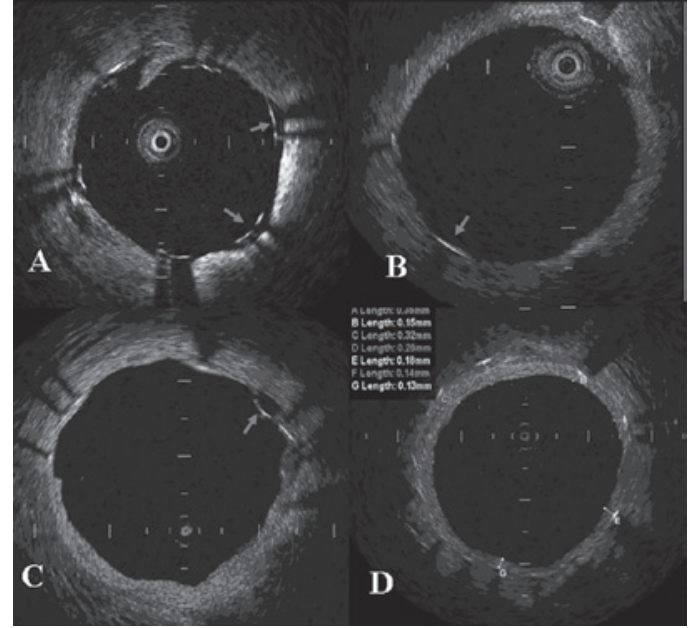

Figure 1. Optical coherence tomography (OCT) imaging and analysis. (A) Malapposition after stent implantation (arrow). (B) Intimal uncoverage at 1-year follow up (arrow). (C) Late malapposition at 1-year follow up (arrow). (D) Measurement of intimal thickness.

lipid-rich or mixed using previously validated criteria (8-11). OCT evaluation of stent malapposition, tissue prolapse, in-stent thrombosis and stent edge dissection followed stent implantation. For the OCT imaging at 1 year follow-up, each stent strut in the still frame was examined regarding whether the strut was in malapposition and whether there was complete coverage. The average thickness was measured when intimal coverage on the strut was observed (Fig. 1).

Statistical analysis. Continuous variables are expressed as the means \pm standard deviation (SD) and were compared using the t-test on independent samples. Categorical variables were expressed as absolute numbers and percentages compared with $\chi^{2}$ statistics or Fisher's exact test. A multivariable logistic regression analysis was performed to assess independent predictors for coronary positive remodeling. The independent variables included in the model were age, history of diabetes mellitus, hypertension, hypercholesterolemia and smoking, as well as stent category, number, diameter and length. $\mathrm{P}<0.05$ was considered to indicate a statistically significant difference. All the statistical analyses were performed using SPSS 11.5 for Windows (SPSS, Inc., Chicago, IL, USA).

\section{Results}

Baseline characteristics. One hundred patients were included in this study. Percutaneous coronary intervention and OCT procedures were successful and without complications in the 2 groups. The baseline characteristics of the 2 groups are shown in Table I. Demographic baseline characteristics including age, gender and risk factors of coronary heart disease were not significantly different. Similarly, the characteristics of the target vessels and lesions were not significantly different among the 2 groups. The average number of stents placed was higher in the group with biodegradable polymer stents $(1.40 \pm 0.70$ vs. $1.21 \pm 0.50, \mathrm{P}=0.039)$. The stent dilatation pressure $(13.83 \pm 1.86$ vs. $14.19 \pm 1.49 \mathrm{~atm}, \mathrm{P}=0.417)$ and the rate of post-dilatation ( 24 vs. $32 \%, \mathrm{P}=0.373$ ) were not significantly different between the groups. 
Table I. Baseline clinical and procedural characteristics.

\begin{tabular}{|c|c|c|c|}
\hline Characteristics & Biodegradable polymer group $(n=50)$ & Permanent polymer group $(n=50)$ & P-value \\
\hline Age (years), mean $\pm \mathrm{SD}$ & $62.05 \pm 9.65$ & $60.41 \pm 9.46$ & 0.228 \\
\hline Male, n (\%) & $42(84)$ & $37(74)$ & 0.220 \\
\hline Smoking, n (\%) & $13(26)$ & $14(28)$ & 0.822 \\
\hline Hypertension, n (\%) & $27(54)$ & $29(58)$ & 0.687 \\
\hline Hypercholesterolemia, n (\%) & $5(10)$ & $7(14)$ & 0.538 \\
\hline Diabetes mellitus, n (\%) & $17(34)$ & $12(24)$ & 0.271 \\
\hline Statin therapy, n (\%) & $46(92)$ & $48(96)$ & 0.674 \\
\hline Blood glucose (mmol/l) & $6.31 \pm 2.46$ & $6.53 \pm 2.16$ & 0.710 \\
\hline $\mathrm{CHO}(\mathrm{mmol} / \mathrm{l})$, mean $\pm \mathrm{SD}$ & $4.38 \pm 1.20$ & $4.20 \pm 1.03$ & 0.533 \\
\hline LDL-C (mmol/l), mean \pm SD & $2.60 \pm 1.04$ & $2.47 \pm 0.82$ & 0.563 \\
\hline HDL-C $(\mathrm{mmol} / \mathrm{l})$, mean $\pm \mathrm{SD}$ & $1.16 \pm 0.25$ & $1.12 \pm 0.27$ & 0.482 \\
\hline $\mathrm{TG}(\mathrm{mmol} / \mathrm{l})$, mean $\pm \mathrm{SD}$ & $1.67 \pm 0.95$ & $1.58 \pm 0.92$ & 0.705 \\
\hline Target vessel, n (\%) & & & 0.112 \\
\hline LAD & $31(62)$ & $37(74)$ & \\
\hline LCX & $13(26)$ & $5(10)$ & \\
\hline RCA & $6(12)$ & $8(16)$ & \\
\hline Lesion length $(\mathrm{mm})$, mean \pm SD & $20.01 \pm 6.04$ & $21.23 \pm 5.07$ & 0.125 \\
\hline Diameter stenosis $(\%)$, mean $\pm \mathrm{SD}$ & $87.16 \pm 4.75$ & $88.05 \pm 5.76$ & 0.230 \\
\hline Stent $(n)$, mean \pm SD & $1.40 \pm 0.70$ & $1.21 \pm 0.50$ & 0.039 \\
\hline Stent diameter $(\mathrm{mm})$, mean $\pm \mathrm{SD}$ & $3.10 \pm 0.45$ & $3.15 \pm 0.34$ & 0.377 \\
\hline Stent length $(\mathrm{mm})$, mean \pm SD & $23.65 \pm 5.83$ & $24.95 \pm 5.21$ & 0.099 \\
\hline Stent dilatation pressure (atm), mean \pm SD & $13.83 \pm 1.86$ & $14.19 \pm 1.49$ & 0.417 \\
\hline Post dilatation, n (\%) & $12(24)$ & $16(32)$ & 0.373 \\
\hline
\end{tabular}

$\mathrm{CHO}$, cholesterol; LDL-C, low-density-lipoprotein-cholesterol; HDL-C, high-density-lipoprotein-cholesterol; LAD, left anterior descending; LCX, left circumflex; RCA, right coronary artery.

Table II. Plaque characterisistics and vessel response after stent implantation.

\begin{tabular}{|c|c|c|c|}
\hline Characteristics & Biodegradable polymer group $(n=50)$ & Permanent polymer group $(n=50)$ & P-value \\
\hline Plaque characteristics & & & 0.66 \\
\hline Lipid-rich plaque, n (\%) & $24(48)$ & $23(46)$ & - \\
\hline Fibrous-lipid plaque, n (\%) & $21(42)$ & $19(38)$ & - \\
\hline Mixed plaque, n (\%) & $5(10)$ & $8(16)$ & - \\
\hline TIMI grade III after stenting, n (\%) & $50(100)$ & $50(100)$ & - \\
\hline Stent struts malapposition, n (\%) & $5(10)$ & $6(12)$ & 0.749 \\
\hline Tissue prolapse, n (\%) & $19(38)$ & $26(52)$ & 0.159 \\
\hline Stent edge dissection, n (\%) & $1(2)$ & $2(4)$ & 0.558 \\
\hline Thrombosis, n (\%) & $3(6)$ & $5(10)$ & 0.461 \\
\hline
\end{tabular}

TIMI, thrombolysis in myocardial infarction.

Clinical and coronary angiography follow-up. The patients were followed up clinically 1 year after stent implantation. There was no major acute coronary event in the group with biodegradable polymer stents. A total of 46 patients (92\%) in the group with biodegradable polymer stents and 45 patients (90\%) with permanent polymer stents had a coronary angiography follow-up at 1 year after stent implantation $(\mathrm{P}=0.727)$. In the group with permanent polymer stents, 2 patients had 
Table III. OCT analysis at follow-up.

\begin{tabular}{|c|c|c|c|}
\hline Variables & Biodegradable polymer group & Permanent polymer group & P-value \\
\hline Patients, n (\%) & $43(86)$ & $41(82)$ & 0.585 \\
\hline Months after stenting (n) & $12.4 \pm 1.8$ & $11.8 \pm 2.1$ & 0.647 \\
\hline Total stent struts (n) & 4,575 & 5,829 & - \\
\hline Uncovered stent struts, n (\%) & $104(2.27)$ & $109(1.87)$ & 0.145 \\
\hline Stent struts malapposition, n (\%) & $87(1.9)$ & $118(2.02)$ & 0.655 \\
\hline Average intimal thickness $(\mu \mathrm{m})$, mean $\pm \mathrm{SD}$ & $106.12 \pm 80.65$ & $181.20 \pm 146.96$ & $<0.001$ \\
\hline
\end{tabular}

OCT, optical coherence tomography.

Table IV. Distribution of neointimal thickness.

\begin{tabular}{lccr}
\hline Zones $(\%)$ & $\begin{array}{c}\text { Biodegradable } \\
\text { polymer group }\end{array}$ & $\begin{array}{c}\text { Permanent } \\
\text { polymer group }\end{array}$ & P-value \\
\hline A, $\leq 100 \mu \mathrm{m}$ & 62.1 & 35.9 & $<0.001$ \\
$\mathrm{~B}, 101-200 \mu \mathrm{m}$ & 27.3 & 33.5 & 0.304 \\
$\mathrm{C}, 201-300 \mu \mathrm{m}$ & 7.3 & 16.3 & 0.046 \\
$\mathrm{D}, \geq 301 \mu \mathrm{m}$ & 3.3 & 14.3 & 0.005 \\
\hline
\end{tabular}

angina pectoris. Coronary angiography showed that 1 of the patients had in-segment restenosis. This patient underwent target lesion revascularization. The remaining patients underwent coronary positive remodeling at the proximal stent segment.

\section{OCT analysis}

Vessel response after stent implantation. OCT examinations were performed on all the patients after stent implantation. Table II shows the plaque characteristics and vessel responses after stent implantation. The frequencies of lipid-rich (48 vs. 46\%), fibrous-lipid (42 vs. 38\%) and mixed (10 vs. 16\%) plaques of the 2 groups were not significantly different $(\mathrm{P}=0.66)$. The frequencies of prolapse (38 vs. 52\%, $\mathrm{P}=0.159)$, stent strut malapposition (10 vs. $12 \%, \mathrm{P}=0.749)$, edge dissection ( 2 vs. $4 \%, \mathrm{P}=0.558$ ) and small thrombosis (6 vs. $10 \%, \mathrm{P}=0.461$ ) of the stents in the 2 groups were also not significantly different.

OCT results at follow-up. OCT examinations were performed upon the first-year follow-up on 43 patients in the biodegradable polymer group and 41 patients in the permanent polymer group. The frequencies of follow-up in the 2 groups were not significantly different (86 vs. $82 \%$, $\mathrm{P}=0.585)$. Table III shows the OCT analysis at follow-up. A total of 4,575 stent struts in the biodegradable polymer group and 5,829 in the permanent polymer group were analyzed. The uncovered stent struts $(2.27$ vs. $1.87 \%, \mathrm{P}=0.145)$ and stent strut malapposition ( 1.9 vs. $2.02 \%, \mathrm{P}=0.655)$ at 1 year follow-up were not significantly different (Fig. 2), although the frequencies of uncovered stent struts were higher in the biodegradable compared with the permanent polymer group. The average neointimal thickness was lower in the biodegradable compared with the permanent polymer group,

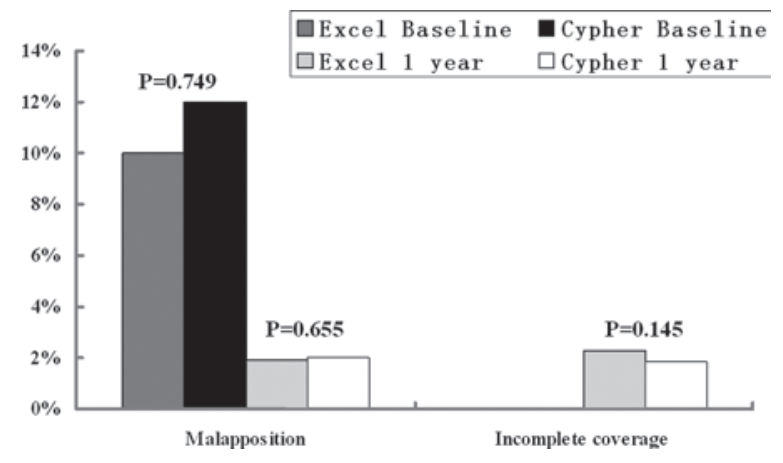

Figure 2. Stent strut malapposition and incomplete coverage.

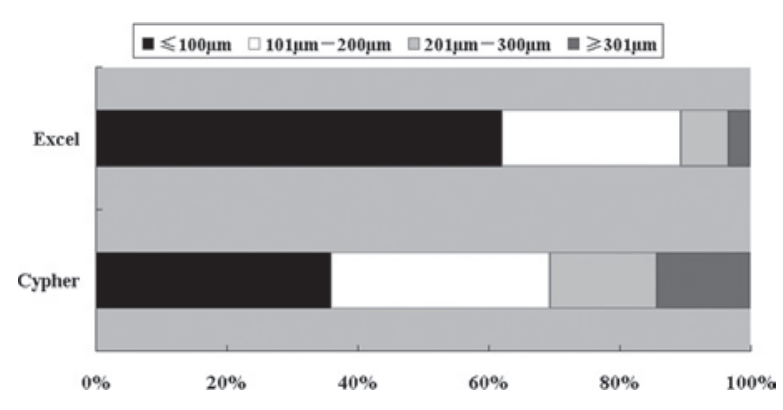

Figure 3. Distribution of neointimal thickness.

and the difference was statistically significant $(106.12 \pm 80.65$ vs. $181.20 \pm 146.96 \mu \mathrm{m}, \mathrm{P}<0.001)$. The neointimal thickness was divided into 4 zones with $100-\mu \mathrm{m}$ intervals, namely, zone A with an intimal thickness of $\leq 100 \mu \mathrm{m}$, zone B with a neointimal thickness of $101-200 \mu \mathrm{m}$, zone $\mathrm{C}$ with a neointimal thickness of 201-300 $\mu \mathrm{m}$ and zone D with a neointimal thickness $\geq 301 \mu \mathrm{m}$. Table IV and Fig. 3 show the distribution of neointimal thickness in the 2 groups. The frequencies of neointimal thickness $<100 \mu \mathrm{m}$ were significantly higher in the biodegradable compared with the permanent polymer group (62.1 vs. $35.9 \%, \mathrm{P}<0.001)$. The average intimal thickness was also lower in the biodegradable compared with the permanent polymer group $(57.7 \pm 24.6$ vs. $67.6 \pm 22.4 \mu \mathrm{m}, \mathrm{P}<0.001)$. The distributions of intimal thickness in zones $\mathrm{C}$ (7.3 vs. $16.3 \%$, $\mathrm{P}=0.046)$ and $\mathrm{D}(3.3$ vs. $14.3 \%, \mathrm{P}<0.005)$ were also lower in the biodegradable compared with the permanent polymer group. No significant difference was found in zone B (27.3 vs. $33.5 \%, \mathrm{P}=0.304)$. 


\section{Discussion}

The present study was a prospective, randomized, open-label study that used OCT to assess intimal hyperplasia following the implantation of the DES with either a biodegradable or permanent polymer. The DES with a biodegradable polymer was found to significantly decrease intimal hyperplasia and to have a well-proportioned coverage compared with DES with a permanent polymer. This finding was associated with an insignificantly higher rate of uncovered stent struts in biodegradable polymer DES at 1-year follow-up after stent implantation.

Stent strut coverage is an important potential surrogate for stent safety. Incomplete stent coverage reported after DES implantation is a risk factor of late stent thrombosis (12). The polymer coating system of drug delivery has been shown to activate chronic arterial wall inflammation, retarding healing and intimal coverage (13). Biodegradable polymers are composed of polylactic acid (PLA), polyglycolide and polymer, which are completely metabolized into water and carbon dioxide after fulfilling their drug delivery function. The safety and effectiveness of biodegradable polymer DES have been demonstrated in previous clinical trials (14-16). However, such studies have not indicated whether biodegradable polymer coatings increase healing and intimal coverage since the included patients were not evaluated with either intravascular sonography or OCT. OCT is a novel imaging modality with a higher resolution compared to travascular sonography used to assess the intimal coverage upon DES follow-up (7). The LEADERS study is a multi-center, head-to-head randomized trial which assessed the safety and effectiveness of biolimus-eluting stents (BES) with a biodegradable polymer and DES with a permanent polymer. Tissue coverage of the stents at the nine-month follow-up was evaluated using OCT in the subgroups of the LEADERS trial. Stent strut coverage appeared to be more complete in patients who were implanted with biodegradable compared with permanent polymer (Cypher $\left.{ }^{\circledR}\right)$ DES (17). However, in the OCTDESI trial, 60 patients with de novo lesions were examined with OCT at the 6-month follow-up; the patients were implanted with paclitaxel-eluting stent (PES) with either permanent polymer (TAXUS ${ }^{\circledR}$ Liberté $^{\circledR}$, Boston Scientific, Natick, MA, USA) or with JACTAX PES (Boston Scientific) with an ultrathin microdot biodegradable abluminal polymer at 2 levels of drug (18). Results showed that JACTAX PES did not improve strut coverage at 6 months compared with PES $\left(5.3 \pm 14.7 \%\right.$ for TAXUS ${ }^{\circledR}, 7.0 \pm 12.2 \%$ for JACTAX HD and $4.6 \pm 7.3 \%$ for JACTAX LD, $\mathrm{P}=0.81$ ).

In the current study, there was no significant difference in the number of uncovered stent struts in the biodegradable and permanent polymer groups ( 2.27 vs. $1.87 \%, \mathrm{P}=0.145)$ at the first-year follow-up. These discrepancies in strut coverage in the various trials may be attributed to several factors.

Firstly, different types of DES with a biodegradable polymer have been used in various clinical trials in which both DES designs and drugs were different. A BES with the biodegradable PLA polymer was used in the LEADERS trial (17); a PES with the biodegradable abluminal polymer was used in the OCTDESI trial (18); and a sirolimus-eluting stent with the biodegradable PLA polymer was used in the current study. A meta-analysis has indicated that different DES with a biodegradable polymer yield different clinical results (19).

Secondly, the OCT follow-up examination periods were not the same [9 months in the LEADERS trial subgroup (17), 6 months in the OCTDESI trial (18) and 1 year in the current study]. Previous studies have indicated that the frequency of incomplete stent coverage gradually decreases with a prolonged follow-up period $(7,20)$. The small number of patients and different inclusion criteria for OCT examination also affected the results of the current study. The uncovered stent struts in the biodegradable polymer DES also indicated that dual antiplatelet treatments for $<1$ year were not safe enough. However, Han et al (21) reported the satisfactory safety and efficacy of DES with a biodegradable polymer when used with 6 months of dual antiplatelet therapy in a real-world setting.

Previous studies have reported that DES has a higher frequency of stent malapposition than occurs with bare metal stents, as assessed by an OCT follow-up $(22,23)$. This finding could be attributed to the fact that the polymer coating may induce vessel wall inflammation and positive remodeling. Similar frequencies of malapposition after the stenting procedure and upon follow-up were detected in the 2 groups in the current study.

Intimal hyperplasia after stent implantation increased late lumen loss and was used to assess stent efficacy. The thickness of intimal coverage was significantly lower in the biodegradable compared with the permanent polymer group $(106.12 \pm 80.65$ vs. $181.20 \pm 146.96 \mu \mathrm{m}, \mathrm{P}<0.001)$, and the distribution of intimal thickness $<100 \mu \mathrm{m}$ was significantly higher in the biodegradable compared with the permanent polymer group (62.1 vs. 35.9\%, $\mathrm{P}<0.001)$. The distribution of intimal thickness in the group with biodegradable polymer DES was similar to the result of the LEADERS subgroup trial (17). Hence, the biodegradable polymer DES was more efficient in preventing stent restenosis due to its biodegradable polymer stent design. The biodegradable polymer had the advantage of completely eluting drugs and decreasing chronic arterial wall inflammation. Distinctive inflammatory responses (e.g., giant cell infiltration, progressive granulomatous and eosinophilic reaction) around the stent struts with a permanent polymer have been detected in previous studies $(24,25)$. Chronic inflammation stimulates intimal hyperplasia and decreases stenting efficacy.

The present study has limitations with regard to its singlecenter source and the small sample population. Larger patient populations from more centers are needed to confirm the results. The biodegradable and permanent polymer DES have different metal platforms, and the metal of the biodegradable polymer DES is thinner compared with that of the permanent polymer DES. The stent structure also results in different intimal hyperplasia and stent malapposition. Although OCT is presently the highest resolution technique, it could not detect a thin intimal coverage $(<10 \mu \mathrm{m})$. This limitation may have increased the frequency of uncovered stent struts during the OCT imaging analysis. In conclusion, biodegradable polymer DES resulted in significantly lower intimal hyperplasia and well-proportioned intimal coverage compared with permanent polymer DES. 


\section{Acknowledgements}

This study was supported by a grant from the National High-Technology Research and Development Program ('863' Program) of China (no. 2009AA02Z420).

\section{References}

1. Iakovou I, Schmidt T, Bonizzoni E, et al: Incidence, predictors, and outcome of thrombosis after successful implantation of drug-eluting stents. JAMA 293: 2126-2130, 2005.

2. Kuchulakanti PK, Chu WW, Torguson R, et al: Correlates and long-term outcomes of angiographically proven stent thrombosis with sirolimus- and paclitaxel-eluting stents. Circulation 113 1108-1113, 2006.

3. McFadden EP, Stabile E, Regar E, et al: Late thrombosis in drug-eluting coronary stents after discontinuation of antiplatelet therapy. Lancet 364: 1519-1521, 2004.

4. Guagliumi G, Farb A, Musumeci G, Valsecchi O, Tespili M, Motta $\mathrm{T}$ and Virmani R: Images in cardiovascular medicine. Sirolimus-eluting stent implanted in human coronary artery for 16 months: pathological findings. Circulation 107: 1340-1341, 2003.

5. Byrne RA, Joner M and Kastrati A: Polymer coatings and delayed arterial healing following drug-eluting stent implantation. Minerva Cardioangiol 57: 567-584, 2009.

6. Takano M, Inami S, Jang IK, Yamamoto M, Murakami D, Seimiya K, Ohba T and Mizuno K: Evaluation by optical coherence tomography of neointimal coverage of sirolimus-eluting stent three months after implantation. Am J Cardiol 99: 1033-1038, 2007.

7. Matsumoto D, Shite J, Shinke T, Otake H, Tanino Y, Ogasawara D, Sawada T, Paredes OL, Hirata K and Yokoyama M: Neointimal coverage of sirolimus-eluting stents at 6-month follow-up: evaluated by optical coherence tomography. Eur Heart J 28: 961-967, 2007.

8. Yabushita H, Bouma BE, Houser SL, Aretz HT, Jang IK, Schlendorf KH, Kauffman CR, Shishkov M, Kang DH, Halpern EF and Tearney GJ: Characterization of human atherosclerosis by optical coherence tomography. Circulation 106: 1640-1645, 2002.

9. Jang IK, Tearney GJ, MacNeill B, Takano M, Moselewski F, Iftima N, Shishkov M, Houser S, Aretz HT, Halpern EF and Bouma BE: In vivo characterization of coronary atherosclerotic plaque by use of optical coherence tomography. Circulation 111 $1551-1555,2005$

10. ManfriniO,MontE,LeoneO,ArbustiniE,EusebiV,VirmaniR and Bugiardini R: Sources of error and interpretation of plaque morphology by optical coherence tomography. Am J Cardiol 98 $156-159,2006$.

11. Kume T, Akasaka T, Kawamoto T, Ogasawara Y, Watanabe N, Toyota E, Neishi Y, Sukmawan R, Sadahira Y and Yoshida K: Assessment of coronary arterial thrombus by optical coherence tomography. Am J Cardiol 97: 1713-1717, 2006.

12. Kotani J, Awata M, Nanto S, Uematsu M, Oshima F, Minamiguchi H, Mintz GS and Nagata S: Incomplete neointimal coverage of sirolimus-eluting stents: angioscopic findings. J Am Coll Cardiol 47: 2108-2111, 2006.

13. Joner M, Finn AV, Farb A, Mont EK, Kolodgie FD, Ladich E, Kutys R, Skorija K, Gold HK and Virmani R: Pathology of drug-eluting stents in humans: delayed healing and late thrombotic risk. J Am Coll Cardiol 48: 193-202, 2006.
14. Onuma Y, Serruys P, den Heijer P, et al: MAHOROBA, first-in-man study: 6-month results of a biodegradable polymer sustained release tacrolimus-eluting stent in de novo coronary stenoses. Eur Heart J 30: 1477-1485, 2009.

15. Byrne RA, Kastrati A, Massberg S, et al: Biodegradable polymer versus permanent polymer drug-eluting stents and everolimusversus sirolimus-eluting stents in patients with coronary artery disease: 3 -year outcomes from a randomized clinical trial. J Am Coll Cardiol 58: 1325-1331, 2011.

16. Windecker S, Serruys PW, Wandel S, et al: Biolimus-eluting stent with biodegradable polymer versus sirolimus-eluting stent with durable polymer for coronary revascularisation (LEADERS): a randomised non-inferiority trial. Lancet 372: 1163-1173, 2008

17. Barlis P, Regar E, Serruys PW, et al: An optical coherence tomography study of a biodegradable vs. durable polymer-coated limus-eluting stent: a LEADERS trial sub-study. Eur Heart J 31: 165-176, 2010.

18. Guagliumi G, Sirbu V, Musumeci G, et al: Strut coverage and vessel wall response to a new-generation paclitaxel-eluting stent with an ultrathin biodegradable abluminal polymer: Optical Coherence Tomography Drug-Eluting Stent Investigation (OCTDESI). Circ Cardiovasc Interv 3: 367-375, 2010.

19. Ahmed TA, Bergheanu SC, Stijnen T, Plevier JW, Quax PH and Jukema JW: Clinical performance of drug-eluting stents with biodegradable polymeric coating: a meta-analysis and systematic review. EuroIntervention 7: 505-516, 2011.

20. Kim JS, Jang IK, Kim JS, Kim TH, Takano M, Kume T, Hur NW, Ko YG, Choi D, Hong MK and Jang Y: Optical coherence tomography evaluation of zotarolimus-eluting stents at 9-month follow-up: comparison with sirolimus-eluting stents. Heart 95: 1907-1912, 2009

21. Han Y, Jing Q, Xu B, et al: Safety and efficacy of biodegradable polymer-coated sirolimus-eluting stents in 'real-world' practice: 18-month clinical and 9-month angiographic outcomes. JACC Cardiovasc Interv 2: 303-309, 2009.

22. Gonzalo N, Barlis P, Serruys PW, Garcia-Garcia HM, Onuma Y, Ligthart J and Regar E: Incomplete stent apposition and delayed tissue coverage are more frequent in drug-eluting stents implanted during primary percutaneous coronary intervention for ST-segment elevation myocardial infarction than in drug-eluting stents implanted for stable/unstable angina: insights from optical coherence tomography. JACC Cardiovasc Interv 2: 445-452, 2009

23. Guagliumi G, Costa MA, Sirbu V, et al: Strut coverage and late malapposition with paclitaxel-eluting stents compared with bare metal stents in acute myocardial infarction: optical coherence tomography substudy of the Harmonizing Outcomes with Revascularization and Stents in Acute Myocardial Infarction (HORIZONS-AMI) Trial. Circulation 123: 274-281, 2011.

24. Finn AV, Nakazawa G, Kolodgie FD and Virmani R: Temporal course of neointimal formation after drug-eluting stent placement: is our understanding of restenosis changing? JACC Cardiovasc Interv 2: 300-302, 2009.

25. Finn AV, Kolodgie FD, Harnek J, Guerrero LJ, Acampado E, Tefera K, Skorija K, Weber DK, Gold HK and Virmani R: Differential response of delayed healing and persistent inflammation at sites of overlapping sirolimus- or paclitaxel-eluting stents. Circulation 112: 270-278, 2005. 